\title{
Thyroid gland dysfunction and its effect on the cardiovascular system: a comprehensive review of the literature
}

\author{
Navid Ahmadi', Faisal Ahmadi', Masehullah Sadiqi ${ }^{\circledR 1}$, Katarzyna Ziemnicka ${ }^{\circledR 2}{ }^{2}$, Andrzej Minczykowski@1 \\ ${ }^{1}$ Chair and Department of Cardiology-Intensive Therapy and Internal Diseases, Poznan University of Medical Sciences, Poznan, \\ Poland \\ ${ }^{2}$ Chair and Department of Endocrinology, Metabolism, and Internal Diseases, Poznan University of Medical Sciences, Poznan, \\ Poland
}

\begin{abstract}
There is an intimate and functional relationship between the cardiovascular system and the thyroid gland; from sharing the same embryologic origin to modulating each of the components of the heart for a normal function. Due to this relationship, patients suffering from cardiovascular diseases often undergo a thyroid function test to rule out hypo- or hyperthyroidism. The signs and symptoms of hyper- and hypothyroidism are clinically relevant and profound. The cardiac function changes can be explained through the cellular mechanism of the thyroid hormone action on the heart. Minor alteration of thyroid hormone can change vascular resistance, cardiac contractility, blood pressure, and heart rhythm, because of the presence of the thyroid hormone receptors on these tissues. A better understanding of the impact of thyroid hormones on the cardiovascular system is paramount for physicians to make a quick decision and initiate a treatment plan because it has been shown to reverse some of the cardiac changes such as systolic and diastolic dysfunction. With this literature review, we aim to describe the holistic effect of thyroid hormones on the cardiovascular system, from its effect on a cellular level to changes in cardiac functions in subclinical and overt hypo/hyperthyroidism. Additionally, we will describe the effects of the drug treatment regimen of thyroid on the cardiac function. (Endokrynol Pol 2020; 71 (5): 466-478)
\end{abstract}

Key words: cardiovascular system; hypertension; hyperthyroidism; hypothyroidism; thyroid hormones

\section{Introduction}

Cardiovascular disease (CVD) remains the single largest cause of death worldwide. Its association with the endocrine system, especially the thyroid gland, has shown to have a significant impact on the cardiovascular system (CVS). The heart and the thyroid gland are derived from the same embryological origin during ontogeny. In an attempt to lower the incidence of CVD, optimal primary and secondary prevention such as the control of hormone disturbances is paramount [1-3].

The thyroid gland releases thyroxine (T4) and triiodothyronine (T3), under the direct control of the thyroid-stimulating hormone (TSH), released from the pituitary. The active T3 hormone has a direct impact on the heart through both genomic and non-genomic pathways. Studies have shown a positive link between subclinical and overt hypothyroidism and an increase in CVD. Moreover, heart failure, a final clinical event of CVD, is highly associated with changes in thyroid hormones (TH) [1-3].
In this review article, we will focus on the following:

- the physiological effect of TH on the CVS at the cellular level;

- thyroid gland dysfunction associated with dyslipidaemia and venous thromboembolism;

- TH and arrhythmias;

- the effect of subclinical and overt hypo/hyperthyroidism on cardiac functions monitored by echocardiography;

- thyroid gland dysfunction and heart failure;

- the impact of different thyroid drugs on the heart.

\section{Thyroid hormone (TH) action on cardiovascular muscles at the cellular level}

The thyroid gland is an essential endocrine organ that produces two main hormones: thyroxine (T4) and triiodothyronine (T3). While T4, a prohormone, has some effect on the body, the vast majority of the biological action is mediated via $\mathrm{T} 3$, which is more potent 
than T4. The majority of $\mathrm{T} 4$ is converted into the active form (T3) by $5^{\prime}$-deiodinase type I or II. TH is crucial for metabolism, growth, and development of the human body. The hypothalamus-pituitary-thyroid axis strictly regulates the $\mathrm{TH}$ level in the body. Thyroid-releasing hormone (TRH) excreted from the hypothalamus activates the release of TSH from the anterior pituitary, which in turn acts on the thyroid gland to produce TH. TH levels affect the levels of TRH and TSH production, forming a feedback loop mechanism [4].

\section{TH and the cardiac muscles}

TH can have both genomic (delayed) and non-genomic (rapid) action. The genomic activity of T3 is mediated through binding to nuclear thyroid hormone receptors (TR) - specifically to $\operatorname{TR} \alpha$ and $\operatorname{TR} \beta[5,6]$. Before T3 binds to TR and exert its effects it has to enter the target cell. TH enters the cell via membrane transporters, predominantly through monocarboxylate transporters (MCT) 8 and 10. As mentioned above, T4 is converted to T3 through $5^{\prime}$-deiodinase type I or II. The resultant T3 enters the nucleus of the target cell and binds to the specific TR with a high affinity. TR are essentially ligand-dependent transcription factors, and once attached to the ligand (T3) they dimerise with other nucleus receptors such as retinoid $X$ receptor (RXR) [7]. These TR-RXR complexes regulate expression of target genes by binding to the thyroid hormone response element (TRE) in the upstream promoter region as homoor heterodimers and recruit other transcriptional cofactors. Based on the cofactors bound, the promoter region can either activate or repress transcription of the gene $[5,6]$. Transcriptional cofactors can be coactivators or corepressors. Coactivators bind to the nuclear receptor and increase gene transcription by acetylating histones and promoting transcription. Corepressors, on the other hand, promote gene repression by recruiting histone deacetylases [8]. This process is illustrated in Figure 1.

In the human heart, $\mathrm{TR} \alpha$ is the predominant form of TR isoform and has both contractile and electrophysiological effects on the heart [9]. This is supported by the fact that TR $\beta$-deficient mice had a normal TH-dependent increase in heart rate, whereas mice that lacked TR $\alpha$ experienced bradycardia [9]. Thyroid hormone exerts its effect on the heart by positively regulating specific genes and decreasing transcription of other genes. The list of cardiac genes that are positively and negatively regulated is presented in Table 1 [6].

Cardiac myocyte contractility is dependent on myosin heavy chains (MHC) $\alpha$ and $\beta$. While $\alpha \mathrm{MHC}$, the fast myosin, is upregulated, $\beta \mathrm{MHC}$ in contrast is negatively regulated by T3 [4]. Additionally, sarcoplasmic reticulum calcium ATPase (SERCA2) is also involved in myocyte contractility and it is the most crucial target of T3 [10]. SERCA2 sequesters calcium back into the sarcoplasmic reticulum during the relaxation phase of myofilament contraction. SERCA2 is positively regulated by $\mathrm{T} 3$, whereas phospholamban (PLB), its inhibitory counterpart, is negatively regulated. The phosphorylation state of PLB governs the action of SERCA2 ion transport capability, and phosphorylated PLB decreases the ability of SERCA2 to pump Ca ${ }^{2+}$ back into the sarcoplasmic reticulum $[4,10]$. The overall effect of T3 is that calcium cycling is increased, resulting in optimal cardiac myocyte relaxation and contraction [4]. Therefore, insufficient serum T3 levels can play a significant role in heart disease, specifically resulting in diastolic dysfunction, which will be discussed in detail later [10].

Even though the vast majority of $\mathrm{TH}$ effect on the heart is mediated through nuclear receptors, $\mathrm{TH}$ can also elicit a rapid impact on the cardiomyocyte and vasculature through the use of ion transport channels that do not rely on protein synthesis ${ }^{4}$. Through in-vitro and in-vivo models, it has been shown that TH can exert nongenomic action by interacting with membrane integrin receptors and by affecting signal transduction pathways in the cytoplasm [11]. Many functions including growth, metabolism, and development are regulated through phosphorylation and activation of kinase pathways, which are extranuclear actions of the TH [12]. Another nongenomic effect of TH involves binding with the $\mathrm{TH}$ receptor integrin $\alpha \mathrm{v} \beta 3$. This receptor activates PI3K and ERK1/2, which are involved in various signal transduction pathways and stimulate transcription of genes such as hypoxia-inducible factor $1 \alpha$ (HIF1 $\alpha$ ) by activating the Akt/PKB pathway $[13,14]$. This process can be seen in Figure 1. These extranuclear or nongenomic actions of TH also include rapid recruitment of slowly inactivating sodium channels, stimulation of $\mathrm{Ca}^{2+}$ ATPase activity, and increasing the activity of $\mathrm{Na}^{+} / \mathrm{K}^{+}$ATPase. Because the levels of THs are relatively stable in the body, their action on these channels may determine the basal myocardial excitability and duration of action potential [9]. The non-genomic effect of TH on the heart is significant because it has been shown that it can have cardioprotective effects on the ischaemic animal heart. Stimulation of the membrane $\mathrm{Na}^{+} / \mathrm{H}^{+}$antiport (NHE) by $\mathrm{TH}$ has been shown to preserve myocardial function $[9,15]$.

\section{TH effect on the vasculature}

In addition to the effect of $\mathrm{TH}$ on the heart, it also has a genomic and non-genomic action on vascular smooth muscle (VSM) cells. Non-genomic effects of TH target the membrane ions and endothelial nitric oxide synthase, which acts as a paracrine hormone in the VSM 


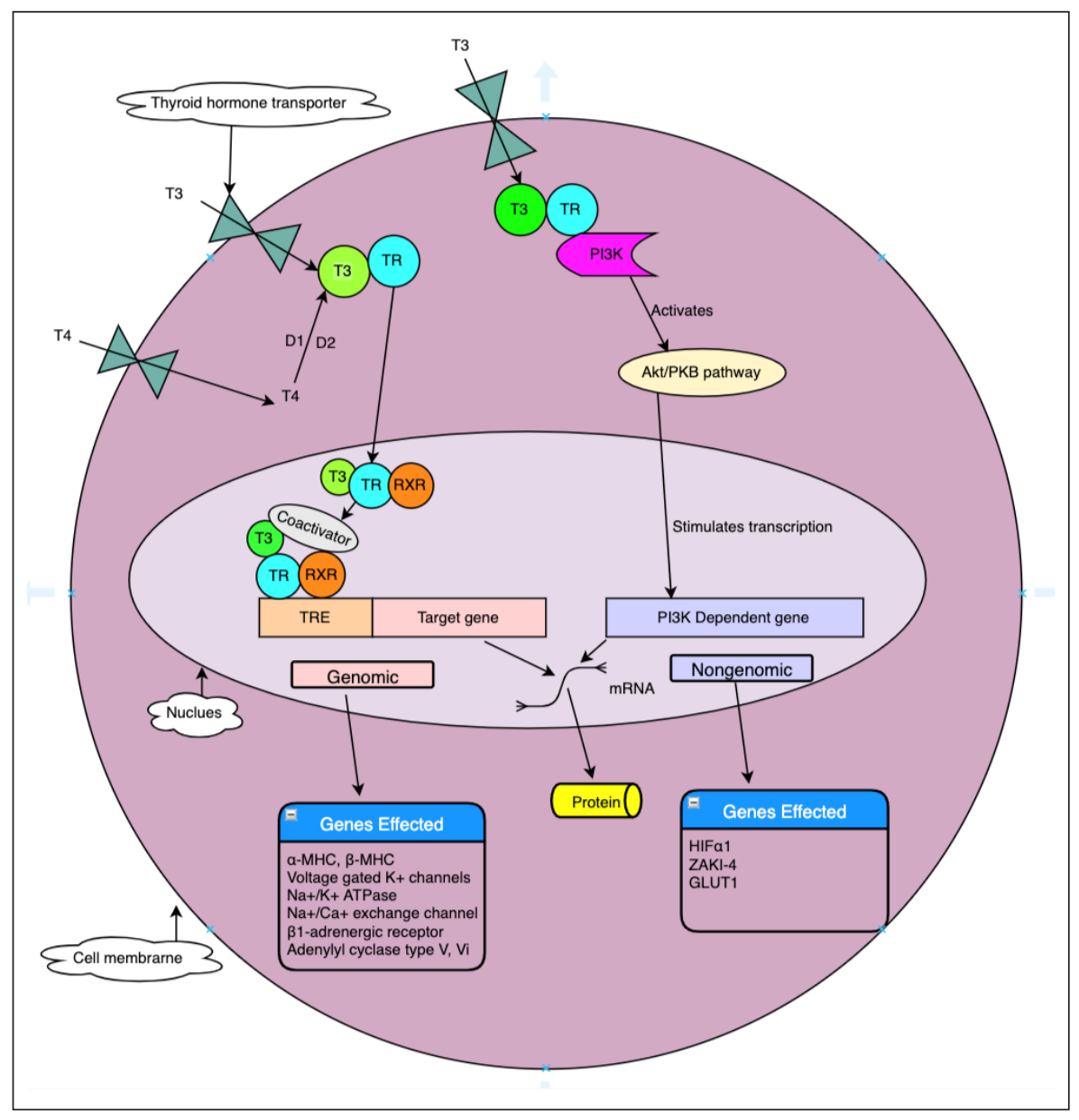

Figure 1. Genomic and non-genomic action of TH. In the genomic pathway, TH enters the target cell via thyroid hormone transporters such as MCT 8 and 10. T4 is converted to T3 by deiodinase type I and type II (D1 and D2). Next, T3 binds to the TR and translocate into the nucleus where it dimerises with RXR. The T3-TR-RXR complex then binds to the TRE located in the promoter region and with the help of coactivators stimulates the transcription of target genes. In the non-genomic pathway, TH binds to the TR and activates the PI3K. In turn, PI3K activates the Akt/PKB cascade, which leads to the upregulation of genes including hypoxia-induced factor $1 \alpha$ (HIF1 $\alpha), \mathrm{ZAKI}-4 \alpha$, and GLUT4 [7, 11, 14]

Table 1. Cardiac-specific genes that are influenced by the effects of T3 [6, 10]

\begin{tabular}{ll}
\hline Positively regulated & Negatively regulated \\
\hline$\alpha$-myosin heavy chain $(\uparrow$ speed of contraction) & $\beta$-myosin heavy chain $(\downarrow$ speed of contraction) \\
\hline Voltage-gated $\mathrm{K}^{+}$channels & $\mathrm{Na}^{+} / \mathrm{Ca}^{2+}$ exchange channel \\
\hline Sarcoplasmic reticulum Ca2+-ATPase $(\uparrow \mathrm{Ca} 2+$ sequestration) & Phospholamban (SERCA2 inhibition) \\
\hline $\mathrm{Na}^{+} / \mathrm{K}^{+}$ATPase & Adenylyl cyclase type $\mathrm{V}, \mathrm{VI}$ \\
\hline$\beta 1$-adrenergic receptor & Thyroid hormone receptor $\alpha$-1 \\
\hline Adenine nucleotide translocase (ANT1) & Thyroid hormone transport (MCT8, 10) \\
\hline Guanine nucleotide-binding protein $\mathrm{G}_{\mathrm{s}}(\uparrow$ adrenergic effect) & Guanine nucleotide-binding protein $\mathrm{G}_{\mathrm{i}}(\downarrow$ adrenergic effect) \\
\hline Malic enzyme & \\
\hline Atrial natriuretic hormone & \\
\hline
\end{tabular}

to cause vascular relaxation [16]. Relaxation of the VSM results in a drop in the arterial resistance pressure and consequently an increase in cardiac output to compensate for the decrease in SVR. TH also indirectly affects the renin-angiotensin-aldosterone system. TH causes a fall in the SVR, which in turn causes the mean arterial pressure to drop. The juxtaglomerular apparatus of the kidney senses the fall in volume and increases 


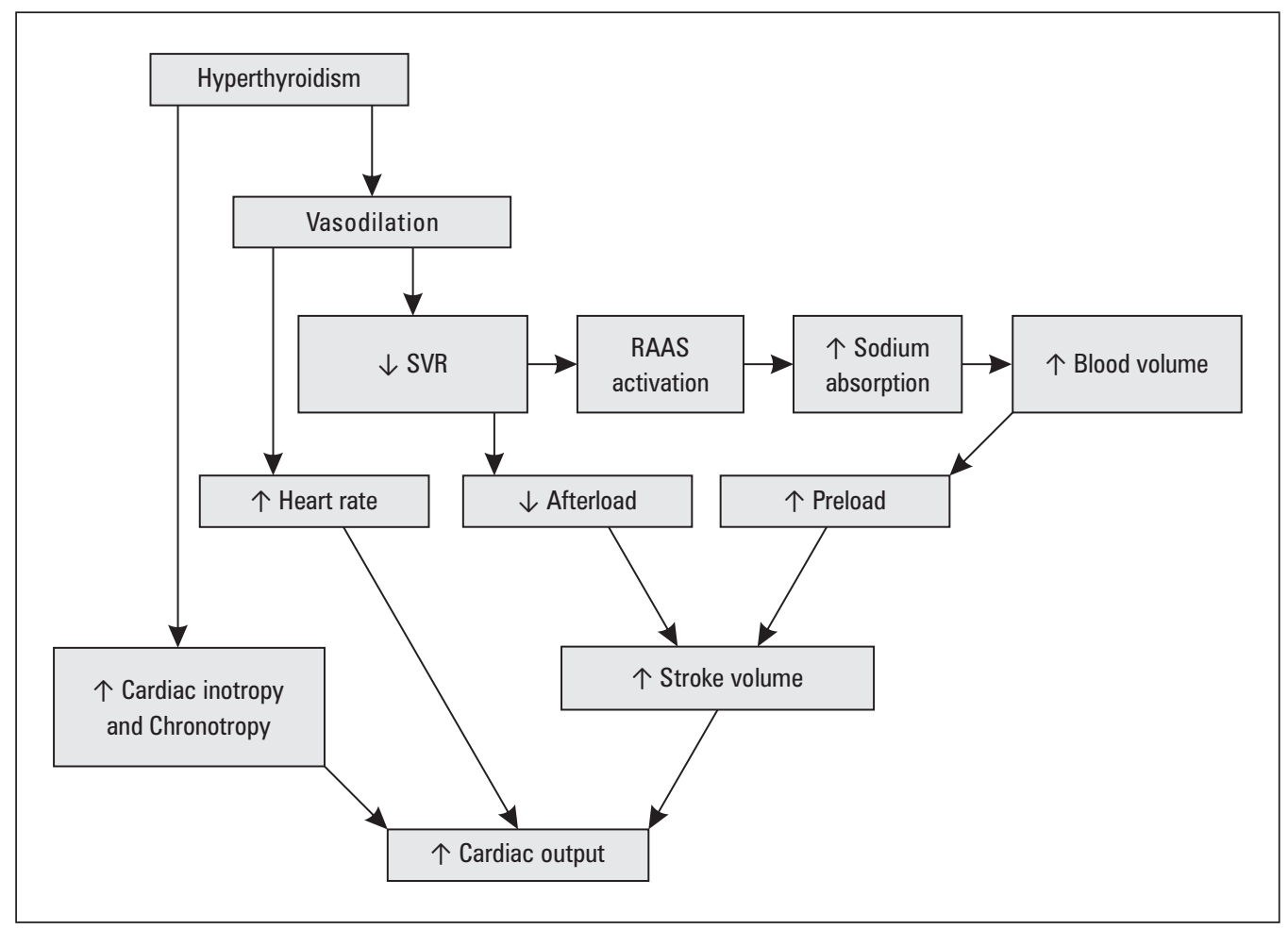

Figure 2. The mechanism by which hyperthyroidism increases cardiac output [17]

synthesis and secretion of renin and subsequently increases retention of $\mathrm{Na}^{+}$. The overall effect of $\mathrm{TH}$ is a decrease in both SVR and afterload but an increase in blood volume and preload, which ultimately increases the cardiac output [16]. Hypothyroidism has far fewer effects on the cardiovascular system than hyperthyroidism. It causes bradycardia, increased peripheral vascular resistance, and mild hypertension [17]. This process is illustrated in Figure 2.

\section{Thyroid hormones and dyslipidaemia}

Mason et al. first established the effect of TH on cholesterol, and since then many studies have associated low TH levels with hypercholesterolaemia and obesity $[18,19]$. A multicentre study found $1-13 \%$ of patients with hypothyroidism to have hypercholesterolaemia, which is often left undetected in the general population [20]. A decrease in $\mathrm{TH}$ inversely correlates with lipid levels; a TSH value of 5.1-10 $\mathrm{ml} \mathrm{U} / \mathrm{L}$ has shown to have a more significant increase in low-density lipoprotein cholesterol (LDL-C) when compared to a healthy control group [21].

Hypothyroidism causes an increase in the synthesis of total cholesterol while reducing degradation, subsequently increasing LDL-C. There is compelling evidence that dyslipidaemia and hypothyroidism cause chronic heart failure, leading to millions of deaths worldwide [22]. Cholesterol synthesis is mediated when T3 recognises sterol regulatory element binding protein (SREBP) in the endoplasmic reticulum. SREBP is then cleaved and transported to the nucleus to bind to transcription factor, sterol regulatory element (SRE), to initiate transcription of LDL receptor (LDLR) and HMG-CoA reductase genes [23, 24]. In hypothyroidism, these steps are diminished, leading to a decrease in LDLR activity as well as reduced control of T3 on the SREBP-2. A low SREBP-2 further reduces HMG-CoA, leading to a decrease in cholesterol levels [23]. Two cross-sectional studies of around 3000 people showed that the aged population with reduced thyroid function had the worst lipid profile when compared to young patients. The study also revealed that a TSH value higher than $5.5 \mathrm{ml} \mathrm{U} / \mathrm{L}$ increased cholesterol levels by $9 \mathrm{mg} / \mathrm{dL}[25,26]$. This dyslipidaemia due to hypothyroidism predisposes to the formation of atherosclerosis, inflammation, and oxidative stress, which all contribute to endothelial dysfunction and cardiovascular disease $[27,28]$. Figure 3 demonstrates these steps.

A meta-analysis study showed that the treatment of hypothyroidism with levothyroxine lowered total cholesterol as well as LDL-C in patients with subclinical hypothyroidism [1]. Current recommendations suggest that treatment to lower hypercholesterolaemia, without any symptoms, should be considered in patients $<65$ years old, especially those suffering from arterial hypertension or dyslipidaemia [29]. The American Association of Clinical Endocrinologists recommends that, 


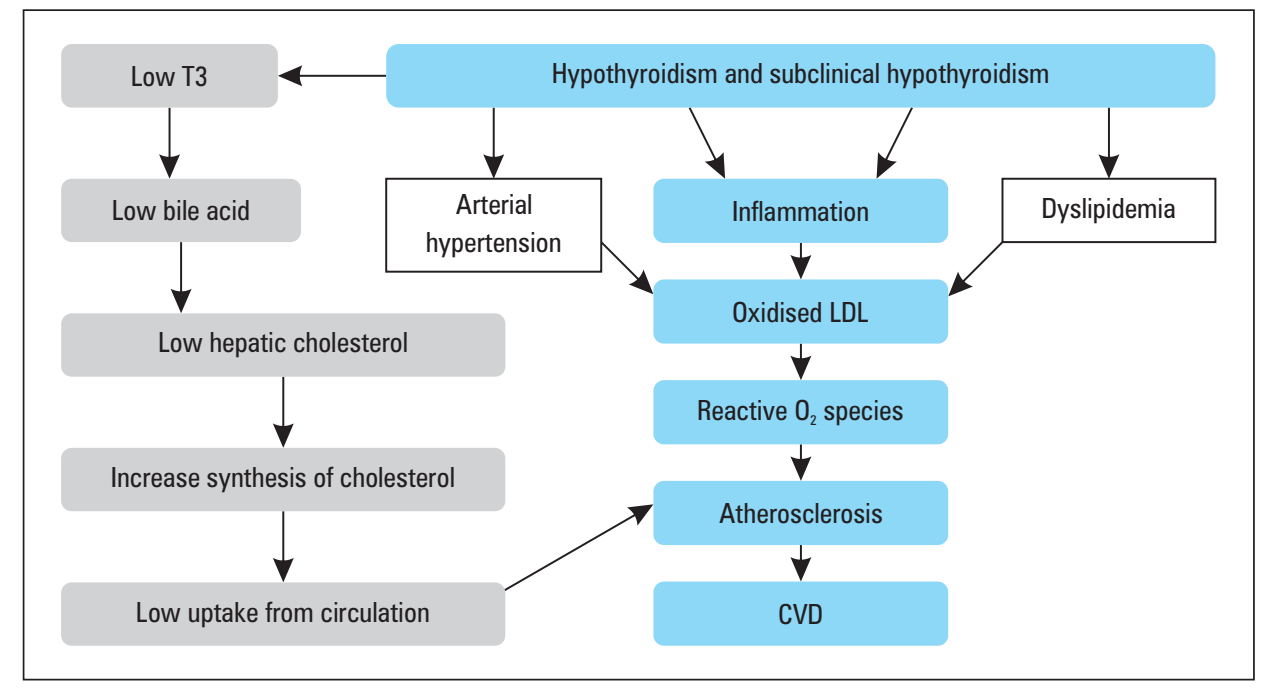

Figure 3. The mechanism by which hypothyroidism leads to the development of atherosclerosis. On the left-hand side, hypothyroidism lowers bile acid flow, followed by a diminution in the rate of cholesterol excretion, which in turn increases intrahepatic cholesterol and reduces uptake from the circulation, contributing to atherosclerosis formation. Additionally, untreated hypothyroidism (including subclinical hypothyroidism) causes arterial hypertension and dyslipidaemia, respectively. This predisposes to inflammation due to oxidative stress and reactive oxygen species, forming atherosclerosis, and leading to cardiovascular disease [27]

before initiating treatment, patients should be closely monitored because levothyroxine has been shown to increase intimal thickness in carotid arteries [21].

\section{Thyroid function and venous thromboembolism (VTE)}

Thyroid hormone dysfunction has been linked to a hypercoagulable state and arterial cardiovascular disease $[30,31]$. At the cellular level, platelets express protein $\alpha \mathrm{v} \beta 3$ that contain receptors for T4 hormone but not for T3. Therefore, hyperthyroidism increases platelet aggregation and increases the risk of thromboembolism [2,32-34]. Also, platelet aggregation is induced by CX3CL1, a chemokine that is regulated from $\alpha \mathrm{v} \beta 3$ by $\mathrm{T} 4$ and thus increases pathologic clotting [34-36]. Angioinvasion, a prothrombotic state could also contribute to this hypercoagulable state $[37,38]$.

The combination of pulmonary embolism (PE) and deep vein thrombosis (DVT), termed as venous thromboembolism (VTE), is associated with numerous complications. One study published in 2004 stated that around 370,000 deaths in six European countries were due to VTE $[39,40]$. A large registry-based study of around 20 million people showed a clear link between hyper- and hypothyroidism and events of VTE in their lifetime. There was nearly a two-fold increase of having a PE in patients suffering from hypothyroidism compared to patients with normal thyroid function $[(0.61 \%$ vs. $0.37 \%$, relative risk $1.64,95 \%$ confidence interval $(\mathrm{CI})$ : $1.63-1.65$, respectively)]. Similarly, $1.36 \%$ of patients with hypothyroidism developed DVT compared to
$0.84 \%$ of patients with normal thyroid function (relative risk 1.62, 95\% CI: 1.61-1.62) [30].

Other case-cohort and case-control studies have also shown a link between hyperthyroidism and risk of VTE $[41,42]$. A recent study by Lerstad et al. showed a two-fold increased risk of VTE in patients with low TSH when compared to healthy patients [39]. This is because hyperthyroidism or subclinical hyperthyroidism increases the release of von Willebrand factor (VWF), plasminogen activator inhibitor-1 (PAI-1), factor III, and factor IX [32, 43]. A multicentre cohort study on VTE recurrence showed that subclinical hyperthyroidism was less likely to cause a recurrent VTE compared to hypothyroidism, which was non-statistically associated with recurrent VTE [44]. A first of its kind study by Lupoli et al. showed that treatment of subclinical hypothyroidism with levothyroxine for six months reversed the prothrombotic state [45]. The results of these studies are summarised in Table 2.

\section{Thyroid hormone and cardiac arrhythmias}

TH influences both the heart rate (chronotropic effect) and the conduction (dromotropic effect). T3 exerts its electrophysiological effect through sodium pump channels and increases $\mathrm{Na}^{+} / \mathrm{K}^{+}$permeability [47]. T3-mediated rise in heart rate is achieved by increased pacemaker ion current in the sinoatrial node [9]. This is corroborated by case studies on humans, which found that the heart rate of hyperthyroid patients was increased throughout the day, whereas hypothyroid 
Table 2. Coagulation factor parameters before and after treatment with levothyroxine. It also illustrates the percentage change in haemostatic and fibrinolytic parameters [46]

\begin{tabular}{lcccc}
\hline & Before treatment & After treatment & Difference & p value \\
\hline FVII (\%) & $123.9 \pm 20.4$ & $102.6 \pm 14.3$ & -17.1 & $<0.001$ \\
\hline FVIII (\%) & $120.4 \pm 19.3$ & $116.5 \pm 16.1$ & -3.2 & 0.182 \\
\hline VWF (\%) & $119.5 \pm 16.6$ & $122.1 \pm 10.2$ & +2.2 & 0.044 \\
\hline D-dimer & $220.3 \pm 67.1$ & $245.2 \pm 103.1$ & +11.3 & 0.053 \\
\hline PAI-1 $[\mathrm{ng} / \mathrm{mL}]$ & $33.6 \pm 13.9$ & $19.4 \pm 7.6$ & -42.3 & $<0.001$ \\
\hline t-PA $[\mathrm{ng} / \mathrm{mL}]$ & $5.56 \pm 2.22$ & $4.43 \pm 1.91$ & -20.3 & 0.002 \\
\hline
\end{tabular}

FVII — factor 7; FVIII — factor 8; VWF — von Willebrand factor; PAI-1 — plasminogen activator inhibitor 1; t-PA — tissue plasminogen activator

patients had a much lower basal, average, and maximal heart rate [48].

Atrial fibrillation (AF), atrial flutter, and sinus tachycardia are the most common dysrhythmias in people suffering from overt or subclinical hyperthyroidism [49, 50]. Between $10 \%$ and $15 \%$ of patients suffering from hyperthyroidism develop AF [51]. Atrial fibrillation is clinically significant because the rapid and irregular heartbeat produced can predispose the individual to form blood clots, which can dislodge and cause an embolism and stroke [9]. Atrial fibrillation is more common in the older population; in one study, $25 \%$ of hyperthyroid patients aged $>60$ years developed AF while the prevalence was only $5 \%$ in patients $<60$ years old [52].

Re-entry is believed to be one of the primary mechanisms by which hyperthyroidism causes AF. Thyroid dysfunction generates multi-circuit wave fronts in the atrium, which predisposes to a fibrillatory rhythm. Development of AF is also associated with a shortened refractory period of atrial cells. Hyperthyroidism may cause AF by reducing the action potential that determines the refractory period; therefore, it increases the likelihood of developing re-entry [17].

Patients with subclinical hyperthyroidism are shown to have a three-times greater chance of developing AF over the subsequent decade compared to those with normal TSH [51]. Thyrotoxic patients are also at a higher risk of developing supraventricular tachycardia, which can result in AF. Ventricular arrhythmias, on the other hand, have a similar rate of occurrence in both healthy and hyperthyroid populations [53].

The link between hyperthyroidism and AF is well established through clinical and experimental studies; however, the impact of hypothyroidism on AF is still unclear [54]. A few case reports have suggested that hypothyroidism might increase the occurrence of AF [3], whereas a population cohort study found an insignificant risk of developing AF in hypothyroid patients [55]. In contrast, a study carried out by Zhang et al. on rats found that both hypothyroidism and hyperthyroidism are associated with increased $\mathrm{AF}$ vulnerability. They found that although hypothyroidism and hyperthyroidism increase AF susceptibility, they have different effects on atrial electrophysiological parameters. While hyperthyroidism increases the heart rate and shortens the effective refractory period (ERP), hypothyroidism effectively does the opposite [54]. Chronic exposure to high TSH levels associated with hypothyroidism prolong the cardiac action potential by increasing the depolarisation of the $\mathrm{Ca}^{2+}$ current and decreasing the repolarising of the $\mathrm{K}^{+}$current [56]. Overt or subclinical hypothyroidism is shown to increase the risk of developing atherosclerosis and myocardial infarction more than arrhythmias [57].

\section{Hypothyroidism and cardiac functions measured by echocardiography}

Hypothyroidism is a commonly encountered condition in which a high TSH and low levels of T3 and T4 are seen. It causes a low cardiac output, a decrease in HR, diastolic dysfunction, and an increase in peripheral vascular resistance. These disorders eventually lead to dilated cardiomyopathy [58, 59]. Overt hypothyroidism is highly associated with pericardial effusion and abnormally increased cholesterol levels [59]. Patients with hypothyroidism have an impaired diastolic function, which can be recognised by echocardiography as prolonged isovolumetric contraction time (IVCT), isovolumetric relaxation time (IVRT), deceleration time of $E$ wave of early mitral inflow velocity (EDT), as well as a reduction in the ratio of mitral inflow early wave velocity (E) to atrial wave velocity (A) ratio (E/A). A low E/A demonstrates a diastolic dysfunction due to reduced relaxation [60]. These patients have also shown a reduced left ventricular global longitudinal strain (LV GLS) even though they might have a normal LVEF [45].

Every patient with overt hypothyroidism is treated with levothyroxine, which leads to improvement in cardiac function. Overall hypothyroidism has a negative impact on the myocardial function. 


\section{Subclinical hypothyroidism $(\mathrm{ScH})$ and the cardiac functions measured by echocardiography}

Subclinical hypothyroidism $(\mathrm{ScH})$ is defined as increased serum thyroid-stimulating hormone (TSH) and normal thyroxine (T4) values. Its prevalence ranges between 4 and 15\%, and females have a higher predisposition than males. Treatment of subclinical hypothyroidism is of debate, but therapy with levothyroxine is indicated when TSH is $>10 \mathrm{mU} / \mathrm{L}[4,61]$. As mentioned above, $\mathrm{TH}$ affects the cardiac function through transcription of a cardiovascular regulatory protein, changes on smooth muscles in the arterial walls, and changes in overall cardiac tissue.

A meta-analysis showed an overall increase of systolic blood pressure in patients with $\mathrm{ScH}$ compared to the control group [62]. No statistically significant difference in the left ventricle (LV) function was observed between $\mathrm{ScH}$ patients and the healthy control groups; however, after treating $\mathrm{ScH}$ patients with levothyroxine, there was a statistically significant difference in the LV function [63-65]. Ozturk S. et al. performed echocardiography in $\mathrm{ScH}$ patients and, using tissue Doppler imaging (TDI), measured the maximal systolic velocity of the mitral valve ring motion $\left(S^{\prime}\right)$, which is a parameter of LV systolic function. They showed a statistically significant reduction of $S^{\prime}$ in patients with $\mathrm{ScH}$ compared to the controlled group; however, levothyroxine treatment did not improve the $S^{\prime}[66]$.

Myocardial performance index (MPI), a parameter measuring global LV systolic function, is generally shown to be abnormal in $\mathrm{ScH}$ patients. MPI values can be reversed with levothyroxine treatment [66, 67]. Global longitudinal strain (GLS) is a better parameter for measuring LV global systolic function, mainly when the ejection fraction (EF) is normal. GLS is significantly lower in ScH patients compared to the control groups; however, levothyroxine treatment has been shown to improve GLS with a statistically significant difference in terms of improvement in $\mathrm{ScH}$ groups. The diastolic function of the heart measured by echocardiography is usually abnormal in $\mathrm{ScH}$ patients. A statistically significant difference was found in the E/A ratio and the ratio of $\mathrm{E}$ wave velocity to early diastolic velocity of mitral valve ring motion measured at the septum ( $\left.E^{\prime}\right)$. The E/A normalised after treatment with levothyroxine for $>6$ months $[66,68]$. Additionally, ScH patients had increased epicardial adipose tissue thickness compared to a control group. This increased thickness is associated with adverse cardiovascular effects and can be reversed with the restoration of the euthyroid state [69].

To summarise, subclinical hypothyroidism does not cause a significant heart problem. However, Sunbul et al. showed an association between impaired LV myocardial function with $\mathrm{ScH}$ patients who were not treated [70]. There are subtle changes in systolic and diastolic $\mathrm{LV}$ function in $\mathrm{ScH}$ patients compared to the control group before and after the treatment, and levothyroxine treatment has been shown to improve LV parameters. However, the American Thyroid Association states that there is not enough evidence showing an improvement in the general quality of life of $\mathrm{ScH}$ patients treated with thyroid hormone [71].

\section{Hyperthyroidism and the cardiac functions measured by echocardiography}

High thyroid hormone is associated with increased HR, decreased total peripheral resistance, increased cardiac output, and increased blood volume [72]. Short-term hyperthyroidism improves haemodynamic parameters by increasing LV contractile function; however, long-term hyperthyroidism increases the risk of myocardial remodelling such as chamber dilatation, heart failure symptoms, and low cardiac output [73].

Graves' disease, the most common cause of hyperthyroidism, is responsible for tachycardia, pulmonary hypertension, and a high output cardiac failure [74]. Pulmonary hypertension occurs in $50 \%$ of cases with Graves' disease, and the incidence increases with high thyroid receptor antibodies and increased cardiac output [75]. A longitudinal study demonstrated that Graves' disease resulted in a hyperdynamic right ventricular function, which can be normalised after treatment. The authors of the study hypothesised that an increased right ventricular preload predisposes to eventual right ventricular failure, which can be reversed by treating the hyperthyroid state [76, 77].

With regard to left heart function, a case-control study showed a high left ventricular end-diastolic diameter (LVEDD) and left ventricular end-systolic diameter (LVESD), compared to the control group. Furthermore, the left atrium volume index and left ventricular mass index were also increased in hyperthyroid patients. These parameters were successfully resolved back to normal after the restoration of euthyroidism [78].

A study with vector flow mapping (VFM), a novel method to visualise and describe a cardiac pathological condition, showed no significant difference in left ventricular ejection fraction (LVEF), left ventricular end-diastolic diameter (LVEDD), and left atrium diameter (LAD) between hyperthyroid patients and the control group $(p>0.05)$. Bozkus et al. also showed that LV systolic haemodynamic increases in a compensatory manner and suggested that VFM could be used to detect early pathological ventricular contraction in clinical 
Table 3. Effect of short-term treatment of overt hyperthyroidism on cardiac parameters. The results are compared when the patients were first diagnosed with hyperthyroid and after six months of treatment [79]

\begin{tabular}{lccc}
\hline & Baseline [mm] & After $\mathbf{6}$ months [mm] & p value \\
\hline MLVDD & $4.1 \pm 0.3$ & $3.8 \pm 0.2$ & $<0.05$ \\
\hline PWTD & $0.9 \pm 0.1$ & $0.8 \pm 0.1$ & $<0.05$ \\
\hline SV & $41.9 \pm 9.9$ & $48 \pm 8.2$ & $<0.05$ \\
\hline SVI & $25.6 \pm 5.4$ & $29.4 \pm 4.7$ & $<0.05$ \\
\hline CO & $3.5 \pm 1.4$ & $3.9 \pm 0.9$ & $<0.05$ \\
\hline Cl & $2.2 \pm 0.8$ & $2.4 \pm 0.5$ & $<0.05$ \\
\hline
\end{tabular}

MLVDD — mean left ventricle diameter in diastole; PWTD — posterior wall thickness in diastole; SV — stroke volume; SVI — stroke volume index; CO — cardiac output; $\mathrm{Cl}$ - cardiac index

settings [79]. A study by Bozkus et al. on the effect of short-term L-thyroxine (LT4) suppression therapy on the cardiac function is shown in Table 3.

Short-term LT4 suppression treatment with LT4 decreased MLVDD and PWTD while increasing SV, SVI, $\mathrm{CO}$, and CI. In addition, LT4 suppression treatment did not have a negative impact on diastolic function, as well as on the cardiac conduction system [80].

\section{Subclinical hyperthyroidism and the cardiac functions measured by echocardiography}

Subclinical hyperthyroidism is defined as a normal range of FT3 and FT4, and low TSH values. Subclinical hyperthyroidism is associated with many CVDs, particularly AF. The prevalence of this disease is common in the general population, and its frequency depends on age, sex, and iodine intake. The elderly population aged $\geq 70$ years have over $15 \%$ incidence of subclinical hyperthyroidism [51]. As mentioned earlier, subclinical hyperthyroidism patients are at a high risk of developing $\mathrm{AF}$, and subsequently, at high risk of stroke [49-51]. However, a relationship between stroke and subclinical hyperthyroidism is unclear. The risk of stroke in this population is linked to their increased predisposition to AF and altered coagulation parameters [1,32].

There are mixed data available on a link between subclinical hyperthyroidism and hypertension. While some studies have shown an increase in blood pressure, others have not found a clear link between subclinical hyperthyroidism and blood pressure [81]. Subclinical hyperthyroidism patients have an increased risk of developing heart failure (HF) $[55,81-83]$. This could be due to an alteration in the heart caused by subclinical hyperthyroidism such as $\mathrm{AF}$ and diastolic dysfunction [81]. A randomised placebo-controlled trial on subclinical hyperthyroid patients showed a diastolic dysfunction during echocardiography, which was reversed with treatment. In this study, the authors found a significantly high mean left ventricular mass, and a high intraventricular septum thickness and posterior wall thickness in subclinical hyperthyroid patients. Fractional shortening and LVEF were lower when compared to the controlled group. Furthermore, diastolic function revealed abnormal values of $\mathrm{E} / \mathrm{A}$ ratio, $\mathrm{E}$ and E' velocities, EDT, and IVRT in subclinical hyperthyroid patients [82]. Finally, a meta-analysis of 290 subjects has shown a 1.4-fold increased risk of all-cause mortality in subclinical hyperthyroidism when compared with euthyroid [84]. In contrast, two meta-analyses showed no link between subclinical hyperthyroidism and cardiovascular mortality $[85,86]$.

\section{Effect of thyroid drugs on the heart}

\section{Levothyroxine}

The use of levothyroxine to treat hypothyroidism has been shown to significantly improve total cholesterol, LDL-cholesterol, triglycerides, diastolic function, hypertension, and heart rate and improves cardiac contractility in patients with cardiomyopathies [16, 97]. Adrees $\mathrm{M}$ et al. observed women receiving levothyroxine for 18 months and noticed the normalisation of elevated systolic and diastolic blood pressure as well as a subsequent reduction in LDL cholesterol levels [97]. Another study showed that patients receiving a placebo presented progression in myocardial diastolic dysfunction, while patients receiving levothyroxine had no significant changes [98]. Levothyroxine has been shown to precipitate arrhythmias and myocardial ischaemia, but its incidence is rarely reported [91].

The European Thyroid Association guidelines recommend treatment with levothyroxine in patients $<65$ years with TSH $>10 \mathrm{mLU} / \mathrm{L}$, although it is still controversial. A reduced dose of $25-50 \mathrm{mcg}$ of levothyroxine is recommended as an initial starting dose for older patients ( $>80$ years) and those suffering from a cardiac disease [29]. 


\section{Radioactive iodine (RAI) and thyroid suppressing drugs}

As mentioned before, untreated hyperthyroidism can cause tachycardia and ventricular dilation, leading to chronic heart failure [99]. Initial treatment with beta-adrenergic blockers is paramount in reducing the heart rate, followed by correction of thyroid dysfunction [16]. While anti-thyroid drugs can reduce the symptoms, they require a very long treatment plan to have an effect. Radioactive iodine (RAI) therapy is frequently used for definitive treatment. However, several studies have shown that radioactive iodine therapy can increase the mortality rate by altering myocardial and vascular impairment, as well as causing other systemic effects. This may appear due to the initial exaggeration of hyperthyroidism caused by the damaging effects of RAI on the gland. It is more frequent in patients with overt than subclinical hyperthyroidism [99, 100]. However, RAI treatment that resulted with hypothyroidism was not associated with increased CVD morbidity compared to other methods of treatment (e.g. thyroidectomy) [101].

\section{Amiodarone}

\section{Amiodarone-induced hypothyroidism}

Amiodarone is widely used in the management of cardiac arrhythmias and has been shown to cause thyroid dysfunction due to iodine load or the intrinsic effects of amiodarone itself [87]. It can cause amiodarone-induced hypothyroidism (AIH) by the Wolff-Chaikoff effect [88]. Amiodarone-induced hypothyroidism is strongly linked with patients from iodine-sufficient areas or the presence of anti-thyroid antibodies [89]. It mainly manifests as primary hypothyroidism, and it is also believed that AIH progresses the pathogenesis of Hashimoto's thyroiditis [90]. If the patient is suffering from a prior thyroid abnormality or amiodarone cannot be withdrawn from the patient, then levothyroxine replacement therapy is recommended $[90,91]$.

\section{Amiodarone-induced thyrotoxicosis}

Amiodarone can cause three types of thyrotoxicosis. Firstly, type 1 amiodarone-induced thyrotoxicosis (AIT 1) is an iodine-induced hyperthyroidism, mainly occurring in nodular goitres [92]. Secondly, type 2 amiodarone-induced thyrotoxicosis (AIT 2), the most frequent form, occurs by destruction of the thyroid gland. Finally, a mixed type may also occur in which a patient may show an overlapping condition [92-94]. Diagnosis usually requires a low TSH and a high serum T3 and T4. Anti-thyroid antibodies are negative in AIT 2 but positive in AIT 1. The use of ultrasound and nuclear medicine in combination are utilised to diagnose and differentiate the different types of AIT [94].
Management of thyrotoxicosis is paramount, especially in patients with cardiac dysfunction or reduced left ventricular ejection fraction (LVEF). Mortality is as high as $30-50 \%$ in AIT patients with low LVEF [94]. Total thyroidectomy is a preferred procedure for patients with severe heart disease, such as ventricular arrhythmias, post-infarction, or congenital heart disease [95].

Amiodarone should be continued in AIT patients if they have life-threatening arrhythmias and in those with poor prognosis. Treatment of AIT 1 is usually by antithyroid drugs and in certain cases by thyroidectomy. Bartalena et al. recommend oral glucocorticoids as the first-line treatment for AIT 2, and if the patient presents as an emergency, then total thyroidectomy is suggested. Thionamide is recommended for patients with mixed form of AIT [96].

\section{Treatment of thyroid cancer and cardiac muscle changes}

Thyroid cancer is the eighth most common cancer in the United States and is predicted to rise to be the fourth leading cancer by 2030 [102]. Thyroid surgery such as thyroidectomy is the mainstay treatment of thyroid cancer, and almost every patient with follicular and papillary thyroid cancer receives post-operative adjuvant RAI. TSH suppression and TSH replacement regimen are often prescribed to reduce the risk of recurrence $[103,104]$. Patients diagnosed with thyroid cancer are usually young and have excellent long-term survival expectancy.

Studies have shown that the use of RAI has a detrimental effect on the gastrointestinal, cardiovascular system and causes salivary dysfunction [105-107]. In addition, long-term TSH suppression increases the risk of cardiovascular-specific mortality and predisposes to pathologic skeletal condition [108-111].

A study of around 4000 thyroid cancer patients after their treatment showed that the proportion of people who died after the treatment were greater in those with CVD compared to patients without CVD $(11.4 \%$ and $2.7 \%$, respectively, $\mathrm{p}<0.001)$. Furthermore, the risk of CVD increased if the patient was male (hazard ratio [HR]: 1.46; 95\% CI: 1.31-1.62), overweight (HR: 1.24; 95\% CI: 1.11-1.39), obese (HR: 1.41; 95\% CI: 1.25-1.60), elderly (HR: 2.84; 95\% CI: 2.24-3.27), those receiving TSH suppression therapy (HR: $1.25 ; 95 \% \mathrm{CI}$ : 1.12-1.40), with another comorbidity (HR: 4.47; 95\% CI: 3.87-5.15), or having distant metastases (HR: 1.35; 95\% CI: 1.03-1.77) [112]. The results of this study are shown in Table 4.

Also, several studies have supported the findings of Park et al., who reported that TSH suppression and RAI 
Table 4. Clinical characteristics of thyroid cancer survivors stratified by cardiovascular disease (CVD) diagnosis [112]

\begin{tabular}{lcccc}
\hline Characteristics & Total $(\mathbf{n}=\mathbf{3 8 2 2})$ & CVD after diagnosis & No CVD & p value \\
\hline Female & 3006 & 1278 & 1728 & $<0.001$ \\
\hline Male & 816 & 441 & 375 & $<0.001$ \\
\hline Overweight & 1145 & 609 & 536 & $<0.001$ \\
\hline Obese & 680 & 415 & 265 & $<0.001$ \\
\hline Dead & 252 & 196 & 56 & $<0.001$ \\
\hline Papillary carcinoma & 3510 & 1564 & 1946 & 0.43 \\
\hline Surgery with radiation & 2006 & 895 & 1111 & 0.40 \\
\hline TSH suppression therapy & 941 & 465 & 476 & 0.002 \\
\hline
\end{tabular}

TSH — thyroid-stimulating hormone

treatment significantly increase the risk of the chronic cardiovascular diseases due to alteration in myocardial and vascular function. A reduction in TSH level increases the risk of cardiovascular mortality by 3.08 (95\% CI: 1.32-7.21) [99, 105, 108, 109]. Another study by Schultz et al., in a cross-sectional survey, showed that $9.7 \%$ of thyroid cancer survivors developed CVD within 10 years of diagnosis and treatment, with men affected more than women [113].

\section{Thyroid hormone and heart failure}

The relationship between heart failure and thyroid dysfunction has been increasingly investigated. T3 has been shown to have cardioprotective effects; therefore, it is no surprise that cardiac function may be impaired in cases of thyroid dysfunction [114]. A small proportion of hyperthyroid patients present with dyspnoea on exertion, oedema, and neck vein distention indicative of congestive heart failure (CHF) [6]. The pathogenesis behind this is explained by the fact that $\mathrm{TH}$ decreases the SVR, which activates the renin-angiotensin-aldosterone system, leading to retention of $\mathrm{Na}^{+}$and fluid. The overall effect of hyperthyroidism is an increase in total blood volume and stroke volume. The cardiac effects of thyroid coupled with low SVR and increased total blood volume result in a high cardiac output state. This can, over time, lead to left ventricular (LV) dysfunction and heart failure [115]. Thyrotoxicosis can also cause tachycardia and can lead to tachycardia-mediated cardiomyopathy (TMC), defined as secondary ventricular dysfunction, which is reversible through the normalisation of heart rate.

Furthermore, hyperthyroidism should be suspected in patients with unexplained right heart failure. The mechanism behind this is believed to be endothelial damage due to high cardiac output, which in turn increases the metabolism of intrinsic pulmonary vasodilators, increasing the pulmonary vascular resistance. Consequently, the right ventricle undergoes hypertrophy because of the increased resistance against which it has to pump [17]. However, it must be noted that CHF due to hyperthyroidism is rare. If patients with high cardiac output are left untreated, they can develop systolic dysfunction and ultimately heart failure, but it is more common in patients with pre-existing heart disease [115]. The lack of TH can also increase the risk of HF [116]. It has been demonstrated through various experimental studies that hypothyroidism can cause cardiac atrophy due to a decrease in $\alpha \mathrm{MHC}$ expression and an increase in $\beta \mathrm{MHC}$ expression. It can also lead to chamber dilation and decreased myocardial blood flow $[117,118]$. Additionally, patients with $\mathrm{HF}$, cardiac surgery, and myocardial infarction have an altered TH metabolism that may result in low serum T3 level, resulting in cardiac dysfunction [119]. HF caused by hypothyroidism is reversible and the American College of Cardiology guidelines for $\mathrm{HF}$ recommend that all new cases of HF must be screened for thyrotropin levels [120].

\section{Conclusion}

Thyroid hormone dysfunction can have a devastating impact on the heart, such as arrhythmias, and systolic and diastolic dysfunction. Hypothyroidism has a different effect on the heart, and treatment with levothyroxine has been shown to improve some of this dysfunction. However, the treatment of subclinical hypothyroidism has been controversial and has mixed results; therefore, a more controlled trial is required for further clarification. It is worth noting that the aging population has to be screened thoroughly when clinical suspicion of any thyroid dysfunction is raised, because this population is more susceptible to detrimental cardiac dysfunction, which may result in death due to thyroid hormone abnormality. 


\section{References}

1. Danese MD, Ladenson PW, Meinert CL, et al. Clinical review 115: effect of thyroxine therapy on serum lipoproteins in patients with mild thyroid failure: a quantitative review of the literature. J Clin Endocrinol Metab. 2000; 85(9): 2993-3001, doi: 10.1210/jcem.85.9.6841, indexed in Pubmed: 10999775.

2. Franchini M, Lippi G, Targher G. Hyperthyroidism and venous thrombosis: a casual or causal association? A systematic literature review. Clin Appl Thromb Hemost. 2011; 17(4): 387-392, doi: 10.1177/1076029610364521, indexed in Pubmed: 20308227.

3. Siddiqui AS, D'Costa DF, Moore-Smith B. Covert hypothyroidism with weight loss and atrial fibrillation. Br J Clin Pract. 1993; 47(5): 268, indexed in Pubmed: 8292476.

4. Razvi S, Jabbar A, Pingitore A, et al. Thyroid Hormones and Cardiovascular Function and Diseases. J Am Coll Cardiol. 2018; 71(16): 1781-1796, doi: 10.1016/j.jacc.2018.02.045, indexed in Pubmed: 29673469

5. Grais IM, Sowers JR. Thyroid and the heart. Am J Med. 2014; 127(8): 691-698, doi: 10.1016/j.amjmed.2014.03.009, indexed in Pubmed: 24662620.

6. Cini G, Carpi A, Mechanick J, et al. Thyroid hormones and the cardiovascular system: pathophysiology and interventions. Biomed Pharmacother. 2009; 63(10): 742-753, doi: 10.1016/j.biopha.2009.08.003, indexed in Pubmed: 19917524.

7. Novodvorsky P, Allahabadia A. Thyrotoxicosis. Medicine. 2017; 45(8): 510-516, doi: 10.1016/j.mpmed.2017.05.013.

8. Mullur R, Liu YY, Brent GA. Thyroid hormone regulation of metabolism. Physiol Rev. 2014; 94(2): 355-382, doi: 10.1152/physrev.00030.2013, indexed in Pubmed: 24692351.

9. Kahaly GJ, Dillmann WH. Thyroid hormone action in the heart. Endocr Rev. 2005; 26(5): 704-728, doi: 10.1210/er.2003-0033, indexed in Pubmed: 15632316

10. Danzi S, Klein I. Thyroid disease and the cardiovascular system. Endocrinol Metab Clin North Am. 2014; 43(2): 517-528, doi: 10.1016/j. ecl.2014.02.005, indexed in Pubmed: 24891175.

11. Cheng SY, Leonard JL, Davis PJ. Molecular aspects of thyroid hormone actions. Endocr Rev. 2010; 31(2): 139-170, doi: 10.1210/er.2009-0007, indexed in Pubmed: 20051527.

12. Cao X, Kambe F, Moeller LC, et al. Thyroid hormone induces rapid activation of Akt/protein kinase B-mammalian target of rapamycin-p70S6K cascade through phosphatidylinositol 3-kinase in human fibroblasts. Mol Endocrinol. 2005; 19(1): 102-112, doi: 10.1210/me.2004-0093, indexed in Pubmed: 15388791.

13. Bergh JJ, Lin HY, Lansing L, et al. Integrin alphaVbeta3 contains a cell surface receptor site for thyroid hormone that is linked to activation of mitogen-activated protein kinase and induction of angiogenesis. Endocrinology. 2005; 146(7): 2864-2871, doi: 10.1210/en.2005-0102, indexed in Pubmed: 15802494.

14. Moeller LC, Cao X, Dumitrescu AM, et al. Thyroid hormone mediated changes in gene expression can be initiated by cytosolic action of the thyroid hormone receptor beta through the phosphatidylinositol 3-kinase pathway. Nucl Recept Signal. 2006; 4: e020, doi: 10.1621/nrs.04020, indexed in Pubmed: 16862226.

15. Mentzer R, Lasley R, Jessel A, et al. Intracellular sodium hydrogen exchange inhibition and clinical myocardial protection. Ann Thorac Surg. 2003; 75(2): S700-S708, doi: 10.1016/s0003-4975(02)04700-8, indexed in Pubmed: 12607715

16. Klein I, Danzi S. Thyroid disease and the heart. Circulation. 2007; 116(15): 1725-1735, doi: 10.1161/CIRCULATIONAHA.106.678326, indexed in Pubmed: 17923583.

17. Hernando V. Role of Thyroid Hormones in Different Aspects of Cardiovascular System. Endocrinol Metab Synd. 2015; 04(02), doi: 10.4172/2161-1017.1000166

18. Mason RL, Hunt HM, Hurxthal L. Blood cholesterol values in hyperthyroidism and hypothyroidism - their significance. N Engl J Med. 1930; 203(26): 1273-1278, doi: 10.1056/NEJM193012252032601.

19. Duntas LH, Brenta G. The effect of thyroid disorders on lipid levels and metabolism. Med Clin North Am. 2012; 96(2): 269-281, doi: 10.1016/j. mcna.2012.01.012, indexed in Pubmed: 22443975.

20. Khazan M, Amouzegar A, Gharibzadeh S, et al. Prevalence of hypothyroidism in patients with dyslipidemia: Tehran Thyroid Study (TTS). Horm Metab Res. 2014; 46(13): 980-984, doi: 10.1055/s-0034-1389997, indexed in Pubmed: 25369072.

21. Willard DL, Leung AM, Pearce EN. Thyroid function testing in patients with newly diagnosed hyperlipidemia. JAMA Intern Med. 2014; 174(2): 287-289, doi: 10.1001/jamainternmed.2013.12188, indexed in Pubmed: 24217672

22. Duntas LH. Thyroid disease and lipids. Thyroid. 2002; 12(4): 287-293, doi: 10.1089/10507250252949405, indexed in Pubmed: 12034052.

23. Damiano F, Rochira A, Gnoni A, et al. Action of Thyroid Hormones, T3 and T2, on Hepatic Fatty Acids: Differences in Metabolic Effects and Molecular Mechanisms. Int J Mol Sci. 2017; 18(4), doi: 10.3390/ijms18040744, indexed in Pubmed: 28362337.
24. Duntas LH, Brenta G. A Renewed Focus on the Association Between Thyroid Hormones and Lipid Metabolism. Front Endocrinol (Lausanne). 2018; 9: 511, doi: 10.3389/fendo.2018.00511, indexed in Pubmed: 30233497.

25. Kanaya AM, Harris F, Volpato S, et al. Association between thyroid dysfunction and total cholesterol level in an older biracial population: the health, aging and body composition study. Arch Intern Med. 2002; 162(7): 773-779, doi: 10.1001/archinte.162.7.773, indexed in Pubmed: 11926850

26. Asvold BO, Vatten LJ, Nilsen TIL, et al. The association between TSH within the reference range and serum lipid concentrations in a population-based study. The HUNT Study. Eur J Endocrinol. 2007; 156(2): 181-186, doi: 10.1530/eje.1.02333, indexed in Pubmed: 17287407.

27. Delitala AP, Fanciulli G, Maioli M, et al. Subclinical hypothyroidism, lipid metabolism and cardiovascular disease. Eur J Intern Med. 2017 38: 17-24, doi: 10.1016/j.ejim.2016.12.015, indexed in Pubmed: 28040402.

28. Karbownik-Lewinska M, Marcinkowska M, Stepniak J, et al. TSH $\geq 2.5 \mathrm{mIU} / 1$ is Associated with the Increased Oxidative Damage to Membrane Lipids in Women of Childbearing Age with Normal Thyroid Tests. Horm Metab Res. 2017; 49(5): 321-326, doi: 10.1055/s-0042-120712, indexed in Pubmed: 28395379.

29. Pearce SHS, Brabant G, Duntas LH, et al. 2013 ETA Guideline: Management of Subclinical Hypothyroidism. Eur Thyroid J. 2013; 2(4): 215-228, doi: 10.1159/000356507, indexed in Pubmed: 24783053.

30. Danescu LG, Badshah A, Danescu SC, et al. Venous thromboembolism in patients hospitalized with thyroid dysfunction. Clin Appl Thromb Hemost. 2009; 15(6): 676-680, doi: 10.1177/1076029609336856, indexed in Pubmed: 19671566.

31. Nyirenda MJ, Clark DN, Finlayson AR, et al. Thyroid disease and increased cardiovascular risk. Thyroid. 2005; 15(7): 718-724, doi: 10.1089/thy.2005.15.718, indexed in Pubmed: 16053389.

32. Debeij J, van Zaane B, Dekkers OM, et al. High levels of procoagulant factors mediate the association between free thyroxine and the risk of venous thrombosis: the MEGA study. J Thromb Haemost. 2014; 12(6): 839-846, doi: 10.1111/jth.12573, indexed in Pubmed: 24679097.

33. Kim DDW, Chunilal S, Young S, et al. A study of venous thrombosis incidence in patients with acute hyperthyroidism. Intern Med J. 2013; 43(4): 361-365, doi: 10.1111/j.1445-5994.2012.02870.x, indexed in Pubmed: 22758384

34. Davis PJ, Mousa SA, Schechter GP. New Interfaces of Thyroid Hormone Actions With Blood Coagulation and Thrombosis. Clin Appl Thromb Hemost. 2018; 24(7): 1014-1019, doi: 10.1177/1076029618774150, indexed in Pubmed: 29742907

35. Davis PJ, Glinsky GV, Lin HY, et al. Actions of Thyroid Hormone Analogues on Chemokines. J Immunol Res. 2016; 2016: 3147671 , doi: 10.1155/2016/3147671, indexed in Pubmed: 27493972.

36. Kubota T, Fukuya Y, Hashimoto R, et al. Possible involvement of chemokine-induced platelet activation in thrombophilic diathesis of antiphospholipid syndrome. Ann N Y Acad Sci. 2009; 1173: 137-145, doi: 10.1111/j.1749-6632.2009.04648.x, indexed in Pubmed: 19758142.

37. Franco IF, Gurrado A, Lissidini G, et al. Floating left innominate vein neoplastic thrombus: a rare case of mediastinal extension of follicular thyroid carcinoma. Phlebology. 2015; 30(2): 140-144, doi: 10.1177/0268355513515209, indexed in Pubmed: 24335091.

38. Ordookhani A, Motazedi A, Burman KD. Thrombosis in Thyroid Cancer. Int J Endocrinol Metab. 2018; 16(1): e57897, doi: 10.5812/ijem.57897, indexed in Pubmed: 29696039.

39. Lerstad G, Enga KF, Jorde R, et al. Thyroid function, as assessed by TSH, and future risk of venous thromboembolism: the Tromsø study. Eur J Endocrinol. 2015; 173(1): 83-90, doi: 10.1530/EJE-15-0185, indexed in Pubmed: 25899580.

40. Cohen AT, Agnelli G, Anderson FA, et al. VTE Impact Assessment Group in Europe (VITAE). Venous thromboembolism (VTE) in Europe. The number of VTE events and associated morbidity and mortality. Thromb Haemost. 2007; 98(4): 756-764, indexed in Pubmed: 17938798.

41. van Zaane B, Squizzato A, Huijgen R, et al. Increasing levels of free thyroxine as a risk factor for a first venous thrombosis: a case-control study. Blood. 2010; 115(22): 4344-4349, doi: 10.1182/blood-2009-11-253724, indexed in Pubmed: 20308594.

42. Debeij J, Dekkers OM, Asvold BO, et al. Increased levels of free thyroxine and risk of venous thrombosis in a large population-based prospective study. J Thromb Haemost. 2012; 10(8): 1539-1546, doi: 10.1111/j.1538-78 36.2012.04818.x, indexed in Pubmed: 22703181

43. Stuijver DJF, van Zaane B, Romualdi E, et al. The effect of hyperthyroidism on procoagulant, anticoagulant and fibrinolytic factors: a systematic review and meta-analysis. Thromb Haemost. 2012; 108(6): 1077-1088, doi: 10.1160/TH12-07-0496, indexed in Pubmed: 23014708.

44. Segna D, Méan M, Limacher A, et al. Association between thyroid dysfunction and venous thromboembolism in the elderly: a prospective cohort study. J Thromb Haemost. 2016; 14(4): 685-694, doi: 10.1111/jth.13276, indexed in Pubmed: 26816339.

45. Liu YW, Tsai WC, Su CT, et al. Evidence of left ventricular systolic dysfunction detected by automated function imaging in patients with heart failure and preserved left ventricular ejection fraction. J Card 
Fail. 2009; 15(9): 782-789, doi: 10.1016/j.cardfail.2009.05.006, indexed in Pubmed: 19879465.

46. Lupoli R, Di Minno MN, Tortora A, et al. Primary and Secondary Hemostasis in Patients With Subclinical Hypothyroidism: Effect of Levothyroxine Treatment. J Clin Endocrinol Metab. 2015; 100(7): 2659-2665, doi: 10.1210/jc.2015-1726, indexed in Pubmed: 25955227.

47. Kim D, Smith TW. Effects of thyroid hormone on sodium pump sites, sodium content, and contractile responses to cardiac glycosides in cultured chick ventricular cells. J Clin Invest. 1984; 74(4): 1481-1488, doi: 10.1172/JCI111561, indexed in Pubmed: 6090505.

48. Polikar R, Feld G, Dittrich H, et al. Effect of thyroid replacement therapy on the frequency of benign atrial and ventricular arrhythmias. J Am Coll Cardiol. 1989; 14(4): 999-1002, doi: 10.1016/0735-1097(89)90479-8, indexed in Pubmed: 2477427.

49. Osman F, Gammage MD, Sheppard MC, et al. Clinical review 142: cardiac dysrhythmias and thyroid dysfunction: the hidden menace? J Clin Endocrinol Metab. 2002; 87(3): 963-967, doi: 10.1210/jcem.87.3.8217, indexed in Pubmed: 11889143.

50. Tribulova N, Knezl V, Shainberg A, et al. Thyroid hormones and cardiac arrhythmias. Vascul Pharmacol. 2010; 52(3-4): 102-112, doi: 10.1016/j. vph.2009.10.001, indexed in Pubmed: 19850152.

51. Sawin CT, Geller A, Wolf PA, et al. Low serum thyrotropin concentrations as a risk factor for atrial fibrillation in older persons. N Engl J Med. 1994; 331(19): 1249-1252, doi: 10.1056/NEJM199411103311901, indexed in Pubmed: 7935681.

52. Agner T, Almdal T, Thorsteinsson B, et al. A reevaluation of atrial fibrillation in thyrotoxicosis. Dan Med Bull. 1984; 31(2): 157-159, indexed in Pubmed: 6723378

53. Olshausen K, Bischoff S, Kahaly G, et al. Cardiac arrhythmias and hear rate in hyperthyroidism. The American Journal of Cardiology. 1989; 63(13): 930-933, doi: 10.1016/0002-9149(89)90142-2.

54. Zhang Y, Dedkov EI, Teplitsky D, et al. Both hypothyroidism and hyperthyroidism increase atrial fibrillation inducibility in rats. Circ Arrhythm Electrophysiol. 2013; 6(5): 952-959, doi: 10.1161/CIRCEP.113.000502, indexed in Pubmed: 24036190.

55. Selmer C, Olesen JB, Hansen ML, et al. The spectrum of thyroid disease and risk of new onset atrial fibrillation: a large population cohort study. BMJ. 2012; 345: e7895, doi: 10.1136/bmj.e7895, indexed in Pubmed: 23186910.

56. Alonso H, Fernández-Ruocco J, Gallego M, et al. Thyroid stimulating hormone directly modulates cardiac electrical activity. J Mol Cell Cardiol. 2015; 89(Pt B): 280-286, doi: 10.1016/j.yjmcc.2015.10.019, indexed in Pubmed: 26497403.

57. Hak AE, Pols HA, Visser TJ, et al. Subclinical hypothyroidism is an independent risk factor for atherosclerosis and myocardial infarction in elderly women: the Rotterdam Study. Ann Intern Med. 2000; 132(4): 270-278, doi: 10.7326/0003-4819-132-4-200002150-00004, indexed in Pubmed: 10681281.

58. Alamdari S, Amouzegar A, Tohidi M, et al. Hypothyroidism and Lipid Levels in a Community Based Study (TTS). Int J Endocrinol Metab. 2016 14(1): e22827, doi: 10.5812/ijem.22827, indexed in Pubmed: 27335579.

59. Qari F. Hypothyroidism Associated with Echocardiographic Abnormalities. Intern Med:Open Access. 2017; 07(02), doi: 10.4172/2165-8048.1000237.

60. Rodondi N, Bauer DC, Cappola AR, et al. Subclinical thyroid dysfunction, cardiac function, and the risk of heart failure. The Cardiovascula Health study. J Am Coll Cardiol. 2008; 52(14): 1152-1159, doi: 10.1016/j. jacc.2008.07.009, indexed in Pubmed: 18804743.

61. Garber JR, Cobin RH, Gharib H, et al. American Association of Clinical Endocrinologists and American Thyroid Association Taskforce on Hypothyroidism in Adults. Clinical practice guidelines for hypothyroidism in adults: cosponsored by the American Association of Clinical Endocrinologists and the American Thyroid Association. Endocr Pract. 2012; 18(6): 988-1028, doi: 10.4158/EP12280.GL, indexed in Pubmed: 23246686

62. Ye Y, Xie H, Zeng Y, et al. Association between subclinical hypothyroidism and blood pressure--a meta-analysis of observational studies. Endocr Pract. 2014; 20(2): 150-158, doi: 10.4158/EP13237.OR, indexed in Pubmed: 24014003.

63. Ozturk S, Alcelik A, Ozyasar M, et al. Evaluation of left ventricular systolic asynchrony in patients with subclinical hypothyroidism. Cardiol J. 2012; 19(4): 374-380, doi: 10.5603/cj.2012.0068, indexed in Pubmed: 22825898.

64. Ozturk S, Dikbas O, Baltacı D, et al. Evaulation of atrial conduction abnormalities and left atrial mechanical functions in patients with subclinical thyroid disorders. Endokrynol Pol. 2012; 63(4): 286-293, indexed in Pubmed: 22933164

65. Ilic S, Tadic M, Ivanovic B, et al. Left and right ventricular structure and function in subclinical hypothyroidism: the effects of one-year levothyroxine treatment. Med Sci Monit. 2013; 19: 960-968, doi: 10.12659/MSM.889621, indexed in Pubmed: 24217559.

66. Nakova VV, Krstevska B, Kostovska ES, et al. The effect of levothyroxine treatment on left ventricular function in subclinical hypothyroidism.
Arch Endocrinol Metab. 2018; 62(4): 392-398, doi: 10.20945/2359-399700 0000052, indexed in Pubmed: 30304103

67. Yazici M, Gorgulu S, Sertbas Y, et al. Effects of thyroxin therapy on cardiac function in patients with subclinical hypothyroidism: index of myocardial performance in the evaluation of left ventricular function. Int J Cardiol. 2004; 95(2-3): 135-143, doi: 10.1016/j.ijcard.2003.05.015, indexed in Pubmed: 15193811.

68. Erkan G, Erkan AF, Cemri M, et al. The evaluation of diastolic dysfunction with tissue Doppler echocardiography in women with subclinical hypothyroidism and the effect of L-thyroxine treatment on diastolic dysfunction: a pilot study. J Thyroid Res. 2011; 2011: 654304, doi: 10.4061/2011/654304, indexed in Pubmed: 21860776.

69. Sayin I, Erkan AF, Ekici B, et al. Thickening of the epicardial adipose tissue can be alleviated by thyroid hormone replacement therapy in patients with subclinical hypothyroidism. Kardiol Pol. 2016; 74(12): 1492-1498, doi: 10.5603/KP.a2016.0053, indexed in Pubmed: 27112940.

70. Sunbul M, Durmus E, Kivrak T, et al. Left ventricular strain and strain rate by two-dimensional speckle tracking echocardiography in patients with subclinical hypothyroidism. Eur Rev Med Pharmacol Sci. 2013; 17(24): 3323-3328, indexed in Pubmed: 24379063.

71. Feller M, Snel M, Moutzouri E, et al. Association of Thyroid Hormone Therapy With Quality of Life and Thyroid-Related Symptoms in Patients With Subclinical Hypothyroidism: A Systematic Review and Meta-analysis. JAMA. 2018; 320(13): 1349-1359, doi: 10.1001/jama.2018.13770, indexed in Pubmed: 30285179.

72. Klein I, Ojamaa K. Thyroid hormone and the cardiovascular system. N Engl J Med. 2001; 344(7): 501-509, doi: 10.1056/NEJM200102153440707, indexed in Pubmed: 11172193

73. Weltman NY, Wang D, Redetzke RA, et al. Longstanding hyperthyroidism is associated with normal or enhanced intrinsic cardiomyocyte function despite decline in global cardiac function. PLoS One. 2012; 7(10): e46655, doi: 10.1371/journal.pone.0046655, indexed in Pubmed: 23056390.

74. Brent G. Graves' Disease. N Engl J Med. 2008; 358(24): 2594-2605, doi: 10.1056/nejmcp0801880, indexed in Pubmed: 18550875.

75. Sugiura T, Yamanaka S, Takeuchi H, et al. Autoimmunity and pulmonary hypertension in patients with Graves' disease. Heart Vessels. 2015; 30(5): 642-646, doi: 10.1007/s00380-014-0518-3, indexed in Pubmed: 24838983

76. Teasdale SL, Inder WJ, Stowasser M, et al. Hyperdynamic Right Heart Function in Graves' Hyperthyroidism Measured by Echocardiography Normalises on Restoration of Euthyroidism. Heart Lung Circ. 2017; 26(6) 580-585, doi: 10.1016/j.hlc.2016.10.007, indexed in Pubmed: 28025026.

77. Gazzana ML, Souza JJ, Okoshi MP, et al. Prospective Echocardiographic Evaluation of the Right Ventricle and Pulmonary Arterial Pressure in Hyperthyroid Patients. Heart Lung Circ. 2019; 28(8): 1190-1196, doi: 10.1016/j.hlc.2018.06.1055, indexed in Pubmed: 30262155.

78. Aroditis K, Pikilidou M, Vourvouri E, et al. Changes in cardiac function and structure in newly diagnosed Graves' disease. A conventional and 2D-speckle tracking echocardiography study. Int J Cardiovasc Imaging. 2017; 33(2): 187-195, doi: 10.1007/s10554-016-0984-z, indexed in Pubmed: 27680576 .

79. Zhou BY, Wang J, Xie MX, et al. Left ventricular systolic intraventricula flow field assessment in hyperthyroidism patients using vector flow mapping. J Huazhong Univ Sci Technolog Med Sci. 2015; 35(4): 574-578, doi: 10.1007/s11596-015-1473-7, indexed in Pubmed: 26223930.

80. Bozkus Y, Sunger A, Yildirir A, et al. Effects of short term mild L-Thyroxine suppression therapy on myocardial functions, and its assessment with tissue Doppler imaging. Minerva Endocrinol. 2016; 41(2): 147-156, indexed in Pubmed: 25389951.

81. Delitala AP. Subclinical Hyperthyroidism and the Cardiovascular Disease. Horm Metab Res. 2017; 49(10): 723-731, doi: 10.1055/s-0043-117893, indexed in Pubmed: 28915531

82 Smit JWA, Eustatia-Rutten CFA, Corssmit EPM, et al Reversible diastolic dysfunction after long-term exogenous subclinical hyperthyroidism: a randomized, placebo-controlled study. J Clin Endocrinol Metab. 2005; 90(11): 6041-6047, doi: 10.1210/jc.2005-0620, indexed in Pubmed: 16131580

83. Gencer B, Collet TH, Virgini V, et al. Thyroid Studies Collaboration. Subclinical thyroid dysfunction and the risk of heart failure events: an individual participant data analysis from 6 prospective cohorts. Circulation 2012; 126(9): 1040-1049, doi: 10.1161/CIRCULATIONAHA.112.096024, indexed in Pubmed: 22821943.

84. Haentjens P, Van Meerhaeghe A, Poppe K, et al Subclinical thyroid dysfunction and mortality: an estimate of relative and absolute excess all-cause mortality based on time-to-event data from cohort studies. Eur J Endocrinol. 2008; 159(3): 329-341, doi: 10.1530/EJE-08-0110, indexed in Pubmed: 18511471.

85. Völzke H, Schwahn C, Wallaschofski H, et al. Review: The association of thyroid dysfunction with all-cause and circulatory mortality: is there a causal relationship? J Clin Endocrinol Metab. 2007; 92(7): 2421-2429, doi: 10.1210/jc.2007-0179, indexed in Pubmed: 17473067.

86. Singh S, Duggal J, Molnar J, et al. Impact of subclinical thyroid disorders on coronary heart disease, cardiovascular and all-cause mortal- 
ity: a meta-analysis. Int J Cardiol. 2008; 125(1): 41-48, doi: 10.1016/j. ijcard.2007.02.027, indexed in Pubmed: 17434631.

87. Bogazzi F, Tomisti L, Bartalena L, et al. Amiodarone and the thyroid: a 2012 update. J Endocrinol Invest. 2012; 35(3): 340-348, doi: 10.3275/8298, indexed in Pubmed: 22433945.

88. Markou K, Georgopoulos N, Kyriazopoulou V, et al. Iodine-Induced hypothyroidism. Thyroid. 2001; 11(5): 501-510, doi: 10.1089/105072501 300176462, indexed in Pubmed: 11396709

89. Leung AM, Braverman LE. Iodine-induced thyroid dysfunction. Curr Opin Endocrinol Diabetes Obes. 2012; 19(5): 414-419, doi: 10.1097/MED.0b013e3283565bb2, indexed in Pubmed: 22820214

90. Cohen-Lehman J, Dahl P, Danzi S, et al. Effects of amiodarone therapy on thyroid function. Nat Rev Endocrinol. 2010; 6(1): 34-41, doi: 10.1038/nrendo.2009.225, indexed in Pubmed: 19935743

91. Udovcic M, Pena RH, Patham B, et al. Hypothyroidism and the Heart. Methodist Debakey Cardiovasc J. 2017; 13(2): 55-59, doi: 10.14797/mdcj-13-2-55, indexed in Pubmed: 28740582.

92. Theodoraki A, Vanderpump MPJ. Thyrotoxicosis associated with the use of amiodarone: the utility of ultrasound in patient management. Clin Endocrinol (Oxf). 2016; 84(2): 172-176, doi: 10.1111/cen.12988, indexed in Pubmed: 26642425.

93. Klein I, Danzi S. Thyroid Disease and the Heart. Curr Probl Cardiol. 2016; 41(2): 65-92, doi: 10.1016/j.cpcardiol.2015.04.002, indexed in Pubmed: 26792255.

94. Bogazzi F, Bartalena L, Martino E. Approach to the patient with amiodarone-induced thyrotoxicosis. J Clin Endocrinol Metab. 2010; 95(6): 2529-2535, doi: 10.1210/jc.2010-0180, indexed in Pubmed: 20525904.

95. Kaderli RM, Fahrner R, Christ ER, et al. Total Thyroidectomy for Amiodarone-induced Thyrotoxicosis in the Hyperthyroid State. Exp Clin Endocrinol Diabetes. 2016; 124(1): 45-48, doi: 10.1055/s-0035-1565094, indexed in Pubmed: 26575117.

96. Bartalena L, Bogazzi F, Chiovato L, et al. 2018 European Thyroid Association (ETA) Guidelines for the Management of Amiodarone-Associated Thyroid Dysfunction. Eur Thyroid J. 2018; 7(2): 55-66, doi: 10.1159/000486957, indexed in Pubmed: 29594056.

97. Adrees M, Gibney J, El-Saeity N, et al. Effects of 18 months of L-T4 replacement in women with subclinical hypothyroidism. Clin Endocrinol (Oxf). 2009; 71(2): 298-303, doi: 10.1111/j.1365-2265.2008.03509.x, indexed in Pubmed: 19094068

98. Fadeyev VV, Sytch J, Kalashnikov V, et al. Levothyroxine replacement therapy in patients with subclinical hypothyroidism and coronary artery disease. Endocr Pract. 2006; 12(1): 5-17, doi: 10.4158/EP.12.1.5, indexed in Pubmed: 16524858 .

99. Biondi B, Cooper DS. Benefits of thyrotropin suppression versus the risks of adverse effects in differentiated thyroid cancer. Thyroid. 2010; 20(2): 135-146, doi: 10.1089/thy.2009.0311, indexed in Pubmed: 20151821.

100. Tomisti L, Materazzi G, Bartalena L, et al. Total thyroidectomy in patients with amiodarone-induced thyrotoxicosis and severe left ventricular systolic dysfunction. J Clin Endocrinol Metab. 2012; 97(10): 3515-3521, doi: 10.1210/jc.2012-1797, indexed in Pubmed: 22865896.

101. Ryödi E, Metso S, Huhtala H, et al. Cardiovascular Morbidity and Mortality After Treatment of Hyperthyroidism with Either Radioactive Iodine or Thyroidectomy. Thyroid. 2018; 28(9): 1111-1120, doi: 10.1089/thy.2017.0461, indexed in Pubmed: 29882483.

102. Rahib L, Smith BD, Aizenberg R, et al. Projecting cancer incidence and deaths to 2030: the unexpected burden of thyroid, liver, and pancreas cancers in the United States. Cancer Res. 2014; 74(11): 2913-2921, doi: 10.1158/0008-5472.CAN-14-0155, indexed in Pubmed: 24840647.

103. Miller KD, Siegel RL, Lin CC, et al. Cancer treatment and survivorship statistics, 2016. CA Cancer J Clin. 2016; 66(4): 271-289, doi: 10.3322/caac.21349, indexed in Pubmed: 27253694.

104. Thyroid Cancer. NCCN.Org/Patients presented with support from: NCCN GUIDELINES FOR PATIENTS $®$. www.thyca.org.

105. Banach R, Bartès B, Farnell K, et al. Results of the Thyroid Cancer Alliance international patient/survivor survey: Psychosocial/informational support needs, treatment side effects and international differences in care. Hormones (Athens). 2013; 12(3): 428-438, doi: 10.1007/BF03401308, indexed in Pubmed: 24121384.

106. Jeong SY, Kim HW, Lee SW, et al. Salivary gland function 5 years after radioactive iodine ablation in patients with differentiated thyroid cancer: direct comparison of pre- and postablation scintigraphies and their relation to xerostomia symptoms. Thyroid. 2013; 23(5): 609-616, doi: 10.1089/thy.2012.0106, indexed in Pubmed: 23153322.

107. Zettinig G, Hanselmayer G, Fueger BJ, et al. Long-term impairment of the lacrimal glands after radioiodine therapy: a cross-sectional study. Eur J Nucl Med Mol Imaging. 2002; 29(11): 1428-1432, doi: 10.1007/s00259-002-0969-0, indexed in Pubmed: 12397459.

108. Sugitani I, Fujimoto Y. Effect of postoperative thyrotropin suppressive therapy on bone mineral density in patients with papillary thyroid carcinoma: a prospective controlled study. Surgery. 2011; 150(6): 1250-1257, doi: 10.1016/j.surg.2011.09.013, indexed in Pubmed: 22136848.

109. Flynn RW, Bonellie SR, Jung RT, et al. Serum thyroid-stimulating hormone concentration and morbidity from cardiovascular disease and fractures in patients on long-term thyroxine therapy. J Clin Endocrinol Metab. 2010; 95(1): 186-193, doi: 10.1210/jc.2009-1625, indexed in Pubmed: 19906785

110. Shargorodsky M, Serov S, Gavish D, et al. Long-term thyrotropin-suppressive therapy with levothyroxine impairs small and large artery elasticity and increases left ventricular mass in patients with thyroid carcinoma. Thyroid. 2006; 16(4): 381-386, doi: 10.1089/thy.2006.16.381, indexed in Pubmed: 16646685.

111. Klein Hesselink EN, Klein Hesselink MS, de Bock GH, et al. Long-term cardiovascular mortality in patients with differentiated thyroid carcinoma: an observational study. J Clin Oncol. 2013; 31(32): 4046-4053, doi: 10.1200/JCO.2013.49.1043, indexed in Pubmed: 24101052.

112. Park J, Blackburn BE, Ganz PA, et al. Risk Factors for Cardiovascular Disease Among Thyroid Cancer Survivors: Findings From the Utah Cancer Survivors Study. J Clin Endocrinol Metab. 2018; 103(7): 2468-2477, doi: 10.1210/jc.2017-02629, indexed in Pubmed: 29850817.

113. Schultz PN, Stava C, Vassilopoulou-Sellin R. Health profiles and quality of life of 518 survivors of thyroid cancer. Head Neck. 2003; 25(5): 349-356, doi: 10.1002/hed.10217, indexed in Pubmed: 12692870.

114. Martinez F. Thyroid hormones and heart failure. Heart Fail Rev. 2016; 21(4): 361-364, doi: 10.1007/s10741-016-9556-5, indexed in Pubmed: 27098905 .

115. Riaz K, Forker AD, Isley WL, et al. Hyperthyroidism: a "curable" cause of congestive heart failure--three case reports and a review of the literature. Congest Heart Fail. 2003; 9(1): 40-46, doi: 10.1111/j.1527-5299.2003.0112 4.x, indexed in Pubmed: 12556677.

116. Rodondi N, Bauer DC, Cappola AR, et al. Subclinical thyroid dysfunction, cardiac function, and the risk of heart failure. The Cardiovascular Health study. J Am Coll Cardiol. 2008; 52(14): 1152-1159, doi: 10.1016/j. jacc.2008.07.009, indexed in Pubmed: 18804743.

117. Galli E, Pingitore A, Iervasi G. The role of thyroid hormone in the pathophysiology of heart failure: clinical evidence. Heart Fail Rev. 2010; 15(2): 155-169, doi: 10.1007/s10741-008-9126-6, indexed in Pubmed: 19110971.

118. Liu Z. Influence of hypothyroidism and the reversal of hypothyroidism on hemodynamics and cell size in the adult rat heart. J Moll Cell Cardiol. 1990; 22(12): 1339-1348, doi: 10.1016/0022-2828(90)90979-c, indexed in Pubmed: 2089154.

119. Mourouzis I, Forini F, Pantos C, et al. Thyroid hormone and cardiac disease: from basic concepts to clinical application. J Thyroid Res. 2011; 2011: 958626, doi: 10.4061/2011/958626, indexed in Pubmed: 21765997.

120. Yancy CW, Jessup M, Bozkurt B, et al. 2017 ACC/AHA/HFSA Focused Update of the 2013 ACCF/AHA Guideline for the Management of Heart Failure: A Report of the American College of Cardiology/American Heart Association Task Force on Clinical Practice Guidelines and the Heart Failure Society of America. Circulation. 2017; 136(6): e137-e161, doi: 10.1161/CIR.0000000000000509, indexed in Pubmed: 28455343. 